\title{
KONTRIBUSI KONVENSI BAHASA ARAB - JAWA TERHADAP HARMONISASI SOSIAL
}

\author{
Muhandis Azzuhri \\ STAIN Pekalongan Jawa Tengah Indonesia \\ hands.azzuhri@gmail.com
}

\begin{abstract}
Abstrak
Penelitian ini membahas tentang sejarah proses percampuran linguistik bahasa Arab - Jawa pada masyarakat Klego Pekalongan, Bentuk konvensi bahasa komunikasi Arab-Jawa pada masyarakat Klego Pekalongan, Kesesuaian konvensi bahasa ArabJawa dengan kaidah linguistik (kaidah derivasi dan makna leksikal), dan Kontribusi konvensi bahasa Arab- Jawa terhadap harmonisasi sosial. Sumber data penelitian ini didapatkan dari bahasa komunikasi campur Arab-Jawa pada masyarakat Klego Pekalongan Timur. Penelitian ini menggunakan pendekatan kualitatif dengan metode wawancara dan dokimentasi. Hasil penelitian menunjukan bahwa sejarah konvensi bahasa Arab-Jawa pada masyarakat Klego bermula dari kedatangan Orang ArabHadramaut-Yaman ke wilayah Klego Pekalongan. Kontribusinya terhadap masyarakat Klego yang heterogen mempengaruhi terhadap keharmonisan sosial antara komunitas keturunan Arab dan Jawa, tidak ada unsur pemaksaan bahasa, budaya dan tradisi diantara mereka. Masing-masing dapat menerima kebudayaannya masing-masing, bahkan bagi keturunan Arab sudah membaur dalam tradisi dan adat istiadat komunitas Jawa.
\end{abstract}

Kata Kunci: Konvensi, Bahasa Arab - Jawa, harmonisasi. 
Muhandis Azzuhri

\section{Abstract}

THE CONTRIBUTION OF ARABIC-JAVANESE CONVENTION TOWARD SOCIAL HARMONIZATION. This study discussed (1) the history of the mixing linguistic process of Arabic - Javanese on Klego community, Pekalongan, (2) conventions form of communication language Arabic - Javanese on Klego community, Pekalongan, (3) convention contribution of Arabic-Java to the rules of linguistics (derivation rules and the lexical meaning), and (4) conventions contributions of language Arab - Java to social harmony. Source of research data was derived from the mixed communication language of Arab - Java in Klego community, East Pekalongan. This study uses qualitative approach by using interview and documentation method. The results showed that the historical conventions of Arabic - Javanese in Klego community was from the arrival of the people from Arab-Hadramaut-Yemen to Klego-Pekalongan. They influenced social harmony of Arab and Javanese community; there is no element of coercion in language, culture and traditions among them. Each can accept each culture, even for those of Arab descent have already integrated into the traditions and customs of the Java community.

Keywords: convention, Arabic - Javanese, harmonization.

\section{A. Pendahuluan}

Setiap negara, tidak terkecuali Indonesia memiliki lebih dari satu bahasa yang digunakan. Bangsa Indonesia mempunyai 500 bahasa yang digunakan oleh penduduknya (Sumarsono, 2008: 76). Karena itu masyarakat Indonesia tergolong kepada masyarakat multilingual (multilingual society). Masyarakat bahasa dapat terjadi salah satunya karena adanya beberapa etnik yang ikut membentuk masyarakat, sehingga dari segi etnik bisa dikatakan sebagai masyarakat majemuk (plural society).

Keanekabahasaan dalam suatu masyarakat biasanya selalu menimbulkan masalah atau paling tidak mengandung potensi akan timbulnya masalah atau sekurang-kurangnya menimbulkan konsekwensi-konsekwensi tertentu. Keanekabahasaan membawa masalah bagi individu-individu dan kelompok individu (terutama yang termasuk minoritas dan pendatang) pada suatu masyarakat. Bagi individu atau kelompok individu minoritas, masalah yang segera timbul ialah mereka harus menguasai sekurang-kurangnya 
dua bahasa, yaitu bahasanya sendiri dan bahasa mayoritas atau juga bahasa pribumi, sebelum mereka dapat berfungsi sebagai anggota penuh masyarakat tinggal mereka.

Jika kelompok minoritas itu merupakan pendatang baru, misalnya para etnis Sunda ke Jawa, mereka harus segera mampu menguasai bahasa Jawa. Mereka yang merupakan generasi pertama paling sulit menghadapi tantangan kebahasaan. Andaikata mereka itu semua orang dewasa, anak-anak mereka, atau generasi kedua, tentu akan semakin berkurang kesulitannya, begitu seterusnya untuk generasi-generasi berikutnya. Gejala kebahasaan di masyarakat semacam ini berlaku juga bagi etnis-etnis yang lain seperti etnis Arab, India, Madura, dan lain sebagainya.

Upaya saling mempelajari dari masing-masing etnis yang berbeda bahasa, dalam telah sosiolinguistik bisa dikatakan sebagai upaya untuk menjaga dan atau melestarikan harmonisasi sosial. Mereka yang mempunyai perbedaan ras atau etnis selalu berupaya melakukan penyesuaian satu sama yang lain atau salah satu diantaranya, sehingga dapat menumbuhkan sejumlah upaya solidaritas budaya yang cukup untuk mendukung terciptanya eksistensi kehidupan yang harmonis di antara mereka.

Penyesuaian budaya yang berwujud solidaritas budaya tersebut, salah satunya berwujud dalam bentuk bahasa. Dengan demikian dapat dikatakan, bahwa bukti adanya adaptasi sosial yang dapat menciptakan kehidupan yang harmonis dapat ditelusuri melalui konvensi linguistik yang terjadi diantara komunitas tutur yang berkontak. Dalam kata lain, terdapat hubungan yang bersifat korelasional antara bahasa dengan interaksi sosial para pemakai bahasa atau varian yang berbeda, yang melakukan kontak tersebut.

Menarik untuk diamati dalam hal ini adalah fenomena sosial bagi kehidupan bermasyarakat di kelurahan Klego Pekalongan Timur. Berdasarkan survey awal ke kelurahan Klego didapatkan sebuah data awal bahwa Klego merupakan nama salah satu kelurahan di Pekalongan Timur - Jawa Tengah yang dihuni oleh 8266 penduduk menurut data sensus bulan Februari 2010 dengan perincian 6.702 penduduk etnis Jawa, 1418 keturunan Arab, 146 keturunan Cina dan 3 warga negara asing (Arab). 
Dengan penduduk yang sangat homogen dari berbagai latar belakang etnis tersebut memunculkan interaksi sosial yang sangat beragam terutama dalam hal bahasa komunikasi. Daerah ini, paling tidak berdasarkan bahasa yang dijadikan identitas atau komunikasi sosial ditemukan dua komunitas tutur bahasa yaitu bahasa Jawa dan bahasa Arab. Kedua bahasa tersebut, bahasa yang jumlah komunitas penuturnya lebih besar adalah bahasa Jawa. Dalam pengamatan sementara, kondisi sosial masyarakat Klego bisa dikatakan harmonis, saling hormat menghormati, sekalipun secara etnis di daerah ini terdapat dua kelompok etnis besar yaitu etnis Jawa dan etnis keturunan Arab. Yang menarik dari kehidupan dua etnis ini adalah kerukunan sosial terjadi. Kerukunan atau keakraban antara masyarakat etnis Arab dan etnis Jawa salah satunya dapat dilihat dari proses percampuran bahasa serta ragam tutur yang mereka gunakan.

Proses alih kode serta campur kode antara bahasa Arab dan Jawa sudah sangat lumrah dilakukan di daerah ini. Gejala kebahasaan tersebut seakan-akan sudah tidak lagi dianggap sebagai gejala kekacauan bahasa, akan tetapi sebaliknya ragam campur bahasa di atas sudah menjadi lingua franca bagi masyarakat Klego Pekalongan.

Fenomena komunikasi campur kode Jawa - Arab, atau sebaliknya bukanlah suatu yang aneh bagi masyarakat Klego yang dikenal sebagai "Kampung Arab" di Pekalongan ini. Sehingga apabila kita berada di daerah ini seringkali kita akan mendapatkan percakapan campur kode dalam komunikasi kesehariannya. Hal ini dilakukan baik oleh orang-orang keturunan Arab maupun orangorang Jawa. Diantara campur kode Arab - Jawa dalam komunikasi adalah; ente pak endi? (kamu mau kemana?), aku pak requd sik (saya mau tidur dulu), anaku pak zuwaj (anak saya mau nikah), dan lain sebagainya. Akan tetapi munculnya kata-kata Arab yang muncul pada kalimat campur kode di atas, secara leksikal maknanya sangat mudah difahami, terlebih lagi bagi masyarakat Jawa yang sedikit memahami bahasa Arab.

Gejala kebahasaan inilah yang mendorong peneliti untuk melakukan penelitian. Gejala bahasa yang terjadi adalah semacam konvensi bahasa (kesepakatan dalam menggunakan kata-kata tertentu). Sehingga dengan adanya konvensi tersebut, baik itu 
masyarakat keturunan Arab maupun Jawa sama-sama menggunakan dan memahaminya sehingga terjadi harmonisasi sosial diantara mereka.

Melihat latar belakang penelitian ini berusaha menjawab: 1) Bagaimana proses percampuran linguistik bahasa Arab - Jawa pada masyarakat Klego - Pekalongan?, 2) Bagaimana bentuk konvensi bahasa komunikasi Arab - Jawa yang digunakan pada masyarakat Klego - Pekalongan?, 3) Bagaimana kesesuaian konvensi bahasa Arab - Jawa dengan kaidah linguistik (kaidah derivasi dan makna leksikal)?, 4) Bagaimana kontribusi konvensi bahasa Arab - Jawa terhadap harmonisai sosial pada masyarakat Klego Pekalongan?

Sedangkan signifikansi dari penelitian ini diharapkan dapat dipakai sebagai bahan bagi para leksikon untuk menulis kamus percakapan bahasa Arab kolokial khas etnis keturunan Arab di Pekalongan pada khususnya dan di Indonesia pada umumnya. Selain itu sebagai salah satu referensi mengembangkan teori-teori kajian sosiolinguistik, khususnya aspek campur dan alih kode dan dapat dimanfaatkan oleh komunitas bahasa Arab dalam menambah wawasan keilmuan akan keanekaragaman percakapan bahasa Arab.

Metode penelitian yang digunakan dalam riset ini mencakup dua hal, metode pengumpulan data dan metode analisis data. Metode pengumpulan data linguistik dalam riset ini adalah metode simak dan metode cakap. Dalam metode simak, teknik yang dipakai adalah teknik sadap, yaitu penyimakan dengan menyadap penggunaan bahasa seseorang atau beberapa orang. Dengan teknik sadap ini, cara memperoleh datanya dengan menyadap dan menyimak penggunaan bahasa komunikasi sehari-hari masyarakat Klego Pekalongan dari dua etnis, yaitu Jawa dan Arab sedangkan teknik lanjutannya adalah teknik rekam dan teknik catat. Sedangkan dalam metode cakap, teknik yang dipakai adalah teknik pancing yaitu memancing objek penelitian selaku narasumber agar berbicara. Sedangkan teknik lanjutannya adalah teknik rekam dan teknik catat (Sudaryanto, 1988: 2-9).

Setelah data-data direkam dan dicatat maka dilanjutkan dengan klasifikasi data dengan menggunakan salah satu dari tiga macam transkripsi yang ada, yaitu transkripsi, fonemis atau fonetis, sintaksis dan semantis sesuai dengan objek sasarannya 
Muhandis Azzuhri

(Sudaryanto, 1988: 5).

Sumber data yang dipergunakan adalah sumber data primer dan sekunder. Sumber data primer yaitu bahasa komunikasi campur kode Arab - Jawa di masyarakat Klego Pekalongan Timur. Sedangkan data sekunder adalah data yang diperoleh untuk melengkapi data primer yang diperoleh melalui wawancara mendalam dan terstruktur disertai dokumentasi terkait dengan kehidupan masyarakat Klego Pekalongan.

Pada tahap analisis data ini digunakan metode deskriptif fungsional berdasarkan fungsi bahasa sebagai alat komunikasi. Analisis deskriptif fungsional dilakukan dengan menggunakan metode kontekstual (pendekatan yang memperhatikan konteks situasi) dalam tuturan bahasa campur Arab - Jawa masyarakat Klego Pekalongan.

\section{B. Pembahasan}

\section{Kajian Pustaka}

Penelitian ilmiah yang terkait dengan bahasa dan interaksi sosial barangkali sudah banyak dilakukan. Seperti penelitiannya Mahsun (2002) dengan judul "Bahasa dan Relasi Sosial; telaah kesepadanan adaptasi linguistik dengan adaptasi sosial” Entitas bahasa yang diteliti pada penelitiannya Mahsun adalah bahasa Sasak, bahasa Bali, dan bahasa Sumbawa pada masyarakat Lombok Nusa Tenggara Barat. Penelitian ini berusaha untuk melihat sejauh mana peran interaksi ketiga bahasa tersebut dalam menyelesaikan persoalan-persoalan sosial pada masyarakat tutur setempat. Walaupun penelitian ini dikaitkan dengan kajian sosial, tapi fokus kajian linguistiknya menekankan pada bahasa-bahasa kedaerahan. Sementara untuk entitas fokus penelitiannya bahasa asing (dalam hal ini Arab), sepengetahuan peneliti belum pernah dilakukan.

Penelitian berikutnya yang terkait dengan bahasa dan interaksi sosial adalah penelitian yang dilakukan oleh Fathurrokhman (2009) berjudul "Kode Komunikatif dalam Interaksi Sosial Masyarakat Diglosik di Pedesaan: Kajian Sosiolinguistik di Banyumas”. Penelitian ini berusaha mengungkapkan adanya pemilihan kode komunikatif yang menjadi kendala oleh berbagai faktor sosial, budaya, dan 
situasional serta menjelaskan adanya relasi sosial dan budaya dalam pemakaian bahasa dalam masyarakat diglosik Banyumas.

Berbeda dengan penelitian di atas, penelitian ini memfokuskan diri pada hubungan percampuran bahasa (dalam hal ini adalah bahasa Arab dan bahasa Jawa) kaitannya dengan keharmonisan sosial. Bentuk- bentuk percampuran bahasa tersebut dapat terjadi dengan bentuk alih kode dan campur kode antara bahasa Arab dan Jawa. Menurut penelusuran pustaka yang peneliti lakukan, kajian semacam ini belum pernah ada yang melakukan sebelumnya. Dan kalaupun ada, entitas linguistiknya berbeda seperti yang sudah dilakukan oleh Mahsun pada kajian penelitian di atas.

Teori yang digunakan dalam penelitian ini adalah teori alih kode dan campur kode. Alih Kode adalah sebagai "gejala peralihan pemakaian bahasa karena berubahnya situasi” (Appel, 1976: 79). Sementara Hymes menyatakan alih kode itu bukan hanya terjadi antar bahasa, tetapi dapat juga terjadi antara ragam- ragam atau gayagaya yang terdapat dalam satu bahasa. Seperti beralihnya ragam resmi ke ragam santai suatu bahasa (Hymes, 1973: 103).

Hal ini sejalan dengan apa yang dikatakan Umar dan Napitupulu bahwa alih kode merupakan aspek ketergantungan bahasa dalam suatu masyarakat dwibahasa. Hampir tidak mungkin bagi seorang penutur dalam masyarakat dwibahasa untuk menggunakan satu bahasa saja tanpa terpengaruh bahasa lain yang sebenarnya memang sudah ada dalam diri penutur itu, meskipun hanya sejumlah kosa kata saja. Alih kode dan campur kode dapat terjadi di berbagai situasi dan tempat (Umar, 1994: 13).

\section{Sekilas Masyarakat Klego Pekalongan}

Pekalongan adalah kota kecil dinamis yang berada di Pantai utara pulau Jawa, kedinamisannya diantaranya karena industri dan perdagangan batik yang berlangsung di kota Pekalongan. Kedinamisan perdagangan di kota Pekalongan sudah berlangsung sejak dahulu. Pekalongan di masa dahulu adalah sebuah kota pelabuhan besar sehingga banyak pedagang dari seluruh dunia berdagang di kota tersebut. Pada akhirnya para pedagang itu banyak yang bermukim di kota Pekalongan, di antaranya adalah pedagang dari Cina, India dan Arab. 
Pada masa penjajahan Belanda, golongan etnis tersebut menjadi warna bagi pembagian kelompok pemukiman di kota Pekalongan, lengkapnya terdiri atas pemukiman pribumi, Belanda, Cina dan Arab (India termasuk di dalamnya).

Pemukiman etnis Arab hingga sekarang masih memberikan sentuhan tersendiri bagi warna kota Pekalongan. Bagian wilayah pemukiman ini seringkali disebut Kampung Arab, diantaranya kelurahan Klego. Kelurahan Klego inilah, paling banyak ditemukan komunitas Arab keturunan yang mayoritas berasal dari Arab Yaman (Hadramaut) walaupun tidak menutup kemungkinan banyak juga komunitas Arab keturunan di kelurahan lain seperti kelurahan Sugihwaras, kelurahan Poncol dan banyak kelurahan dan kampung di kota Pekalongan.

\section{Pola-pola dan Struktur Bahasa Kolokial Masyarakat Klego Pekalongan}

Bahasa kolokial atau pada umumnya dinamakan dengan bahasa pasaran (amiyah) merupakan bahasa percakapan yang dilakukan oleh sebuah komunitas masyarakat. Bahasa kolokial berbeda dengan bahasa fushah sebagai bahasa standar yang biasa dipelajari dalam ranah akademis. Sehingga hampir bisa dikatakan bahwa bahasa kolokial itu tidak sesuai kaidah tata bahasa yang baik dan benar, bahkan banyak juga diantaranya tidak terdapat dalam kamus bahasa Arab. Bahasa Arab kolokial yang biasa dipakai oleh masyarakat Klego Pekalongan menunjukan kekhasannya yang hanya bisa dipahami oleh komunitas mereka atau masyarakat yang tinggal bersama mereka walaupun bukan merupakan etnis keturunan Arab.

\section{a. Bahasa campur Arab - Jawa pada masyarakat Klego Pekalongan}

Proses komunikasi, terutama dalam kehidupan bermasyarakat fenomena bahasa campur sering kali ditemukan. Oleh karena itu, fenomena kebahasaan ini sudah menjadi kajian tersendiri dalam kajian sosiolingustik. Dalam kajian linguistik, gejala kebahasaan ini sering disebut sebagai campur kode dan alih kode. Campur kode dan alih kode dapat terjadi di dalam bahasa manapun terutama pada masyarakat yang mempunyai dua komunitas atau lebih bahasa yang berbeda. 
Kontribusi Konvensi Bahasa Arab - Jawa Terhadap Harmonisasi Sosial

Demikian juga gejala campur kode kebahasaan juga terjadi di masyarakat Klego Pekalongan. Seperti yang sudah disebutkan di atas, bahwa di kampung Klego banyak didapati etnis Arab keturunan, dan karena banyaknya jumlah etnis tersebut warga Pekalongan menyebutnya sebagai "kampung Arab". Di satu sisi, sudah jelas bahwa kampung Klego sebagian besar penduduknya adalah pribumi (etnis Jawa). Melihat kodisi seperti ini, akan mudah dilihat bahwa di kampung Klego terdapat dua komunitas etnis serta bahasa yang berbeda. Dengan demikian, gejala bahasa campur yang terjadi pada masyarakat Klego adalah bahasa campur Arab-Jawa.

Dari hasil penelusuran peneliti, bahwa ada beberapa pola bahasa campur yang sering diucapkan oleh warga setempat, baik etnis Arab maupun etnis Jawa. Pola-pola bahasa campur tersebut adalah:

\begin{tabular}{rll}
\hline No & Bahasa Campur Arab-Jawa & Arti \\
\hline 1. & Wah acarane rahhat tenan iki... & Wah acaranya asyik banget \\
\hline 2. & Aku pak regud si' & Saya mau tidur dulu \\
\hline 3. & Panganan iki al tenan & Makanan ini enak banget \\
\hline 4. & Kowe kok das'ah pisan oo... & Kamu kok ganteng banget ya \\
\hline 5. & spidol iki tesiho ono opo wis ghallaq & Spidol ini masih apa sudah \\
\hline 6. & ini sama dengan ini ga? Iyo, loro- & Iya kedua-duanya sama \\
\hline 7. & Aku tak reja sik & Saya mau pulang dulu \\
\hline 8. & Nggak, aku mung softhoh kok & Nggak, saya cuma bercanda \\
\hline 9. & Kowe ngerti ora? Mindrieh & Saya tida mengerti \\
\hline 10. & Pak endi? Bamsyi ning umahe Rudi & Saya mau pergi ke rumah \\
\hline 11. & Lagi Dawwir opo? Dawir sepeda & Lagi cari apa? Cari sepeda \\
\hline 12. & Karo sopo ? karo 'iyal ku & Sama siapa? Sama istriku \\
\hline 13. & Pa' taba nahna ora? & Mau ikut saya enggak? \\
\hline 14. & Abgho asytary sego megono & Saya mau beli nasi megono \\
\hline 15. & Duitku dho' mau bengi & Tadi malam uangku hilang \\
\hline 16. & Aku pa' star pulpen & Saya mau beli pulpen \\
\hline 17. & Wadhon kuwi halli tenan & Perempuan itu cantik sekali \\
\hline 18. & Anaku arep juwaz & Anak saya mau menikah \\
\hline 19. & Ena'e opo yo? Gahwah si' & Enaknua ngapain ya? Minum \\
\hline & &
\end{tabular}


Muhandis Azzuhri

\begin{tabular}{lll}
\hline 20. & Wis yekfi durung? & Sudah cukup belum \\
\hline 21. & Aku ta'abnak ora? & Saya merepotkan kamu tidak? \\
\hline 22. & Ora,...ta'abnakum raahah & Tidak, justru aku seneng \\
\hline 23. & Kuwe Ju' ora? & Kamu lapar tidak? \\
\hline 24. & Saiki Ila fen? & Sekarang kemana? \\
\hline 25. & Bapaku tela' karo aku & Bapak saya lagi marah sama \\
\hline 26. & Wong kuwi ya hanuh tenan & Orang itu sombong sekali \\
\hline 27. & Bisrab ning umah & Minum di rumah \\
\hline 28. & Ban syuf pasar si' & Saya mau lihat pasar dulu \\
\hline 29. & Awas Ghum lak binduq & Awas saya tembak kamu \\
\hline 30. & Wong kae mera 'bal banget & Orang itu nyebelin banget \\
\hline
\end{tabular}

Bahasa campur Arab-Jawa seperti di atas sudah merupakan bahasa keseharian (koloqial) masyarakat klego Pekalongan. Bahasa campur ini seringkali digunakan oleh warga setempat, baik warga ketiurunan Arab maupun enis Jawa asli. Dalam masyarakat Klego semua kata serta struktur bahasa komunikasi yang digunakan sudah merupakan kesepakatan bersama, atau dalam linguistik sering disebut sebagai konvensi bahasa.

b. Kosa kata konvensi bahasa Arab pada masyarakat Klego Pekalongan

Dari hasil penelusuran, bahwa peneliti menemukan sekian banyak konvensi leksikon Arab yang sering digunakan masyarakat Klego, baik orang keturunan Arab sendiri maupun orang Jawa. Kosa kata konvensi bahasa Arab tersebut adalah;

\begin{tabular}{|c|c|c|c|}
\hline No & $\begin{array}{c}\text { Bahasa Campur } \\
\text { Arab-Jawa }\end{array}$ & $\begin{array}{c}\text { Penulisan dalam } \\
\text { huruf Arab }\end{array}$ & Arti \\
\hline 1 & Rahhat & راحة & Asyik/ bagus \\
\hline 2 & Regud & رقد & Tidur \\
\hline 3 & $<\mathrm{Al}$ & عال & Enak \\
\hline 4 & Das'ah & دسعة & Ganteng \\
\hline 5 & Ghallaq & غلّق & Habis \\
\hline 6 & Inah & عينه & Sama \\
\hline 7 & Reja & رجع & Pulang \\
\hline
\end{tabular}


Kontribusi Konvensi Bahasa Arab - Jawa Terhadap Harmonisasi Sosial

\begin{tabular}{|c|c|c|c|}
\hline 8 & Softhoh & صفطة & Bercanda \\
\hline 9 & Mindrieh & من أدريه & Tidak Mengerti \\
\hline 10 & Bamsyi & بأمشى & Pergi \\
\hline 11 & Dawwir & دوّر & Cari \\
\hline 12 & 'Iyal & عيال & Istri \\
\hline 13 & Taba nahna & تبع نحن & Ikut \\
\hline 14 & Abgho asytary & 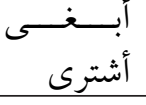 & Mau membeli \\
\hline 15 & Dho' & ضاع & Hilang \\
\hline 16 & Star & أشترى & Membeli \\
\hline 17 & Halli & & Cantik \\
\hline 18 & Juwaz & زواج & Menikah \\
\hline 19 & Gahwah & قهوة & Minum kopi \\
\hline 20 & Yekfi & يكفى & Cukup \\
\hline 21 & Ta'abnak & تعبناك & Merepotkan \\
\hline 22 & Ta'abnakum raahah & تعبنا كم & Tidak merepotkan \\
\hline 23 & $\mathrm{Ju}^{\prime}$ & جوع & Lapar \\
\hline 24 & Ila fen? & إلى فين & Kemana \\
\hline 25 & Tela' & طلع & Marah \\
\hline 26 & Ya hanuh & يا هنوه & Sombong \\
\hline 27 & Bisrab & بشرب & Minum \\
\hline 28 & Bansyuf & بانشوف & Melihat \\
\hline 29 & Ghum lak binduq & قــــــم لك & Menembak \\
\hline 30 & Mera'bal & مرحبل & Nyebelin \\
\hline 31 & Sholi & صلى & Sholat \\
\hline 32 & Harman & حرمان & Suka \\
\hline 33 & Sugul & شغل & Sibuk \\
\hline 34 & $\mathrm{Kul}$ & كل & Makan \\
\hline 35 & Serob & شراب & Minum \\
\hline 36 & Fulus & فلوس & Uang \\
\hline
\end{tabular}


Muhandis Azzuhri

\begin{tabular}{|c|c|c|c|}
\hline 37 & Rejal & رجال & Anak laki-laki \\
\hline 38 & Sohib & صاحب & Teman \\
\hline 39 & Harim & حريم & Istri \\
\hline 40 & Syebe & شيب & Bapak \\
\hline 41 & Umi & أمى & Ibu \\
\hline 42 & Ajus & عجوز & Nenek \\
\hline 43 & Ente & أنتّ & Kamu \\
\hline 44 & Ane & أنا & Saya \\
\hline 45 & Gahwe & قهوة & Kopi \\
\hline 46 & da’jal & دجال & Setan \\
\hline 47 & Tajir & تاجر & Kaya \\
\hline 48 & Majenun & مجنون & Gila \\
\hline 49 & Bahlul & بهلول & Bodoh \\
\hline 50 & Sukron & شكرا & Terima kasih \\
\hline 51 & Afdol & أفضل & Cocok \\
\hline 52 & napsi-napsi & نفسى - نفسى & Sendiri-sendiri \\
\hline 53 & Mut & مَت & Mati \\
\hline 54 & Lebaik & لبيك & Apa/ ada apa? \\
\hline 55 & Jiran & جيران & Tetangga \\
\hline 56 & Bakhil & بخيل & Pelit \\
\hline 57 & Khoir & خير & Baik \\
\hline 58 & Gum & قم & Ayo \\
\hline 59 & Bukhroh & بكرة & Besok \\
\hline 60 & ta`ap & تعب & Letih/ cape \\
\hline
\end{tabular}

c. Kesesuaian pola-pola bahasa konvensi Arab - Jawa pada masyarakat Klego Pekalongan

Dari beberapa kosa kata bahasa Arab kolokial yang peneliti lakukan ada beberapa pola-pola bahasa yang mengalami kesesuaian dengan tata bahasa Arab baku dan ada beberapa diantaranya tidak ada kesesuaian, diantara yang mengalami kesesuaian adalah: 
Kontribusi Konvensi Bahasa Arab - Jawa Terhadap Harmonisasi Sosial

\begin{tabular}{|c|c|c|c|}
\hline No & $\begin{array}{c}\text { Bahasa } \\
\text { Campur Arab- } \\
\text { Jawa }\end{array}$ & $\begin{array}{c}\text { Penulisan } \\
\text { dalam huruf } \\
\text { Arab }\end{array}$ & Penjelasan \\
\hline 1 & Rahhat & راحة & $\begin{array}{l}\text { Kata rahhat Berasal dari kata راحـة } \\
\text { yang punya arti kamus istirahat } \\
\text { atau santai. Karena pengaruh } \\
\text { sosial sesuatu yang bersifat } \\
\text { menyenangkan dibahasakan } \\
\text { dengan kata راحـة. }\end{array}$ \\
\hline 2 & Regud & رقد & $\begin{array}{l}\text { Dalam bahasa } m u^{\prime j a m} \text { atau bahasa } \\
\text { kamus kata } \text { aـempunyai arti } \\
\text { tidur, walaupun ada perbedaan dari } \\
\text { sisi fonetiknya tetapi kata رقد ada } \\
\text { kesesuaian dengan dengan pola } \\
\text { bahasa Arab baku. }\end{array}$ \\
\hline
\end{tabular}

Kata raja berasal dari رجع mempunyai arti pulang, walaupun

3 Reja ada perbedaan dalam fonetiknya tetapi ada kesesuaian dengan tata bahasa Arab baku.

\begin{tabular}{|c|c|c|c|}
\hline 4 & Mindrieh & أدريه & $\begin{array}{l}\text { Kata من أدريـ walaupun diucapkan } \\
\text { dalam bahasa kolokial atau pasaran } \\
\text { tetapi sebenarnya berasal dari kata } \\
\text { ما أدرى yang mempunyai arti saya } \\
\text { tidak tahu. Jadi ada kesesuaian } \\
\text { dengan tata bahasa Arab baku }\end{array}$ \\
\hline 5 & Bamsyi & & $\begin{array}{l}\text { Kata بأمشـى mengandung arti } \\
\text { سـأمشى yaitu saya akan pergi/jalan, } \\
\text { disini mempunyai arti akan, kata } \\
\text { ini ada kesesuaian dengan tata } \\
\text { bahasa Arab baku. }\end{array}$ \\
\hline 6 & Dawwir & دوّر & $\begin{array}{l}\text { Kata دوّر ada kesamaan dalam fonetik } \\
\text { dan kesamaan dalam makna dengan } \\
\text { bahasa Arab baku. دوّر mempunyai } \\
\text { arti carilah. }\end{array}$ \\
\hline
\end{tabular}




\begin{tabular}{|c|c|c|}
\hline 7 & تبع نحن Taba nahna & 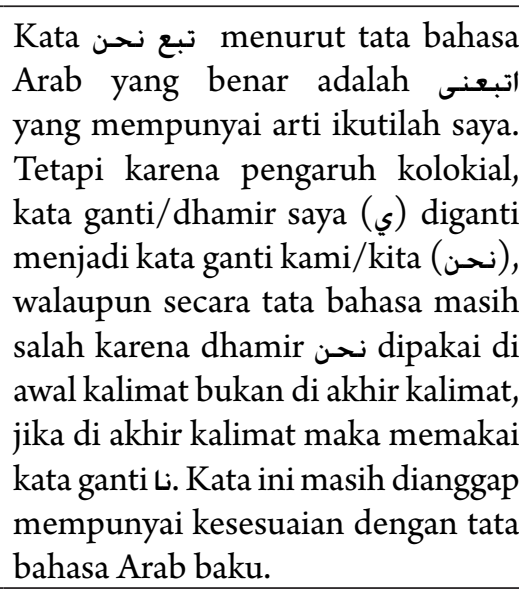 \\
\hline 8 & أبستـــ & $\begin{array}{l}\text { Kata ini mempunyai arti kamus } \\
\text { "saya mau membeli", termasuk } \\
\text { dari bahasa Arab fushah dan ada } \\
\text { kesesuaian dengan tata bahasa Arab } \\
\text { baku. }\end{array}$ \\
\hline 9 & Dho' & $\begin{array}{l}\text { Kata ini mempunyai arti kamus } \\
\text { yaitu hilang, jadi ada kesesuaian } \\
\text { dengan tata bahasa Arab baku. }\end{array}$ \\
\hline 10 & Halli & $\begin{array}{l}\text { Kata ini makna leksikalnya adalah } \\
\text { manis. Berasal dari kata حلوة. Ada } \\
\text { kesesuaian antara bahasa kolokial } \\
\text { dengan bahasa Arab baku atau } \\
\text { fushah. }\end{array}$ \\
\hline 11 & Juwaz & $\begin{array}{l}\text { Kata ini mempunyai arti leksikal } \\
\text { pernikahan/nikah, jadi ada } \\
\text { kesesuaian antara makna kamus } \\
\text { dan bahasa kolokial. Tetapi ada } \\
\text { perbedaan dalam fonetik pada } \\
\text { huruf pertama yang mestinya dibaca } \\
<\text { zawaj }>\text { dalam bahasa Arab fushah } \\
\text { tetapi dibaca }<\text { zuwaj }>\text { dalam bahasa } \\
\text { Arab kolokial. }\end{array}$ \\
\hline 12 & Gahwah & $\begin{array}{l}\text { Kata ini mempunyai arti kopi. Ada } \\
\text { perbedaan dalam pengucapan dalam } \\
\text { bahasa Arab kolokial (gahwah) dan } \\
\text { bahasa Arab baku ( qahwah), tetapi } \\
\text { ada kesesuaian dalam makna }\end{array}$ \\
\hline
\end{tabular}


Kontribusi Konvensi Bahasa Arab - Jawa Terhadap Harmonisasi Sosial

\begin{tabular}{|c|c|c|}
\hline 13 & Yekfi & $\begin{array}{l}\text { Kata ini hanya ada perbedaan } \\
\text { fonetik dengan bahasa fushahnya } \\
\text { yang mestinya dibaca yakfi tetapi } \\
\text { dibaca yekfi dalam bahasa Arab } \\
\text { kolokial percakapan, artinya yaitu } \\
\text { cukup. }\end{array}$ \\
\hline 14 & Ta’abnak & $\begin{array}{l}\text { Kata ini kalau dipahami menurut } \\
\text { bahasa kamus yaitu kami } \\
\text { menyusahkanmu. Bisa juga } \\
\text { diartikan kami merepotkanmu. }\end{array}$ \\
\hline 15 & تعبنا كم Taabnakum & $\begin{array}{l}\text { Kata ini adalah jawaban dari kata } \\
\text { تعبناك sebagai ungkapan basa-basi, } \\
\text { artinya «Tidak merepotkan», } \\
\text { walaupun pemaknaan katanya } \\
\text { mempunyai arti r } \quad \text { «kami } \\
\text { merepotkanmu dengan senang } \\
\text { hati». Etw }\end{array}$ \\
\hline 16 & $\mathrm{Ju}^{\prime}$ & $\begin{array}{l}\text { Kata ini baik bahasa kolokial } \\
\text { maupun fushah mempunyai arti } \\
\text { yang sama yaitu lapar. }\end{array}$ \\
\hline 17 & Sholi & $\begin{array}{l}\text { Kata صلى juga mempunyai arti } \\
\text { yang sama dalam bahasa Arab } \\
\text { kolokial dan bahasa Arab fushah } \\
\text { yaitu mempunyai arti «shalat». }\end{array}$ \\
\hline 18 & Sugul & $\begin{array}{l}\text { Kata ini kalau diucapkan dalam } \\
\text { bahasa Arab fushah maka yang } \\
\text { dilafalkan adalah مشغغول, punya arti } \\
\text { sibuk. Tetapi yang dimaksud dalam } \\
\text { percakapan adalah «kerja } \gg \text {. Jadi } \\
\text { tetap ada persamaan antara bahasa } \\
\text { Arab fushah dan kolokial }\end{array}$ \\
\hline 19 & Kul & $\begin{array}{l}\text { Artinya makan. Tetap ada kesesuaian } \\
\text { antara bahasa arab kolokial dan } \\
\text { fushah. }\end{array}$ \\
\hline 20 & Serob & $\begin{array}{l}\text { Dalam konteks tata bahasa Arab } \\
\text { fushah kata شـراب mempunyai arti } \\
\text { Minuman yang menunjukan kata } \\
\text { benda tetapi dalam pengucapan } \\
\text { kolokial masyarakat Klego } \\
\text { mempunyai arti minum yang } \\
\text { menunjukan kata kerja (fil). }\end{array}$ \\
\hline
\end{tabular}




\begin{tabular}{|c|c|c|c|}
\hline 21 & Fulus & فلوس & $\begin{array}{l}\text { Kata ini menurut makna leksikalnya } \\
\text { berarti uang. }\end{array}$ \\
\hline 22 & Rejal & رجال & $\begin{array}{l}\text { Menurut makna leksikalnya berarti } \\
\text { orang laki-laki }\end{array}$ \\
\hline 23 & Sohib & & $\begin{array}{l}\text { Menurut makna leksikalnya berarti } \\
\text { teman }\end{array}$ \\
\hline 24 & Ummi & أَّ & $\begin{array}{l}\text { Menurut makna leksikalnya berarti } \\
\text { ibu }\end{array}$ \\
\hline 25 & Ajuz & & $\begin{array}{l}\text { Menurut makna leksiklnya berarti } \\
\text { nenek }\end{array}$ \\
\hline 26 & Ane & ان انا & $\begin{array}{l}\text { Kata Lil merupakan isim dhamir } \\
\text { orang pertama tunggal dalam } \\
\text { bahasa Arab dan mempunyai makna } \\
\text { leksikal saya. }\end{array}$ \\
\hline 27 & Ente & انتَ & $\begin{array}{l}\text { Kata انتَ merupakan isim } \\
\text { dhamir orang kedua tunggal dan } \\
\text { mempunyai makna leksikal kamu. }\end{array}$ \\
\hline 28 & Syay & شاي & $\begin{array}{l}\text { Kata شاي menurut makna } \\
\text { leksikalnya adalah teh }\end{array}$ \\
\hline 29 & Majnun & & $\begin{array}{l}\text { Menurut makna leksikalnya berarti } \\
\text { gila. }\end{array}$ \\
\hline 30 & Nafsi-nafsi & نفس - نفس & $\begin{array}{l}\text { Menurut makna leksikalnya berarti } \\
\text { sendiri-sendiri. }\end{array}$ \\
\hline 31 & Jiran & & $\begin{array}{l}\text { Menurut makna leksikalnya berarti } \\
\text { tetangga }\end{array}$ \\
\hline 32 & Tajir & & $\begin{array}{l}\text { Makna leksikalnya ada pedagang, } \\
\text { tetapi dalam bahasa kolokial yang } \\
\text { sudah mengalami konvensi bahasa, } \\
\text { kata ini mempunyai arti orang kaya }\end{array}$ \\
\hline 33 & Sukron & شكر ا & $\begin{array}{l}\text { Antara bahasa fushah dan kolokial } \\
\text { maknanya sama yaitu terima kasih. }\end{array}$ \\
\hline 34 & Afdol & & $\begin{array}{l}\text { Makna leksikal dari kata ini } \\
\text { ada paling utama, tetapi dalam } \\
\text { pemaknaan percakapan kolokial } \\
\text { diartikan dengan cocok }\end{array}$ \\
\hline 35 & Mut & مَتت & $\begin{array}{l}\text { Makna leksikal dari kata ini mati. } \\
\text { Bahasa fushah dan bahasa kolokial } \\
\text { maknanya sama. }\end{array}$ \\
\hline
\end{tabular}


Kontribusi Konvensi Bahasa Arab - Jawa Terhadap Harmonisasi Sosial

\begin{tabular}{|c|c|c|c|}
\hline 36 & Khoir & خير & Makna leksikalnya adalah baik \\
\hline 37 & Gum & قم & $\begin{array}{l}\text { Makna leksikalnya adalah } \\
\text { "berdirilah" tetapi dimaknai dalam } \\
\text { bahasa percakapan dengan arti } \\
\text { "Ayo". }\end{array}$ \\
\hline 38 & ta`ap & & $\begin{array}{l}\text { Makna leksikalnya adalah letih/ } \\
\text { cape. Ada kesamaan antara bahasa } \\
\text { fushah dan bahasa kolokial } \\
\text { percakapan. }\end{array}$ \\
\hline 39 & Syebe & & $\begin{array}{l}\text { Menurut makna leksikal semestinya } \\
\text { diartikan dengan uban dalam } \\
\text { percakapan yang dimaksudkan } \\
\text { dengan "Syebe" itu adalah bapak, } \\
\text { sebab Bapak identik dengan orang } \\
\text { yang sudah beruban }\end{array}$ \\
\hline 40 & da`jal & دجال & $\begin{array}{l}\text { Menurut makna leksikal kata dajjal } \\
\text { diartikan dajjal saja bukan Setan }\end{array}$ \\
\hline 41 & Bahlul & بهلول & $\begin{array}{l}\text { Menurut makna leksikal kata bahlul } \\
\text { berarti jenaka tetapi dalam bahasa } \\
\text { percakapan yang dimaksudkan } \\
\text { adalah bodoh. }\end{array}$ \\
\hline 42 & Ghallaq & غلّق & $\begin{array}{l}\text { Menurut makna leksikal } \\
\text { mempunyai arti tertutup tetapi } \\
\text { dalam bahasa percakapan kolokial } \\
\text { diartikan dengan habis }\end{array}$ \\
\hline 43 & Inah & عينة & $\begin{array}{l}\text { Menurutmaknaleksikalmempunyai } \\
\text { arti bentuk dan diartikan sama } \\
\text { dalam bahasa percakapan kolokial } \\
\text { Klego }\end{array}$ \\
\hline 44 & Tela' & طلع & $\begin{array}{l}\text { Makna leksikal dari kata طلعi } \\
\text { adalah terbit atau muncul tetapi } \\
\text { digunakan menunjukan pada } \\
\text { orang yang muncul kemarahannya. }\end{array}$ \\
\hline
\end{tabular}

$\begin{array}{lll} & & \text { Menurut makna leksikal kata ini } \\ \text { merupakaan mempunyai arti tinggi } \\ \text { tetapi dalam bahasa kolokial Klego } \\ \text { diartikan "enak". }\end{array}$

Sedangkan beberapa kosa kata yang tidak sesuai dengan 
Muhandis Azzuhri

kaidah derivasi dan kaidah leksikal pada bahasa komunikasi masyarakat Klego Pekalongan, adalah sebagai berikut:

\begin{tabular}{|c|c|c|c|}
\hline No & $\begin{array}{c}\text { Bahasa } \\
\text { Campur } \\
\text { Arab-Jawa }\end{array}$ & $\begin{array}{l}\text { Penulisan dalam } \\
\text { huruf Arab }\end{array}$ & Penjelasan \\
\hline 1 & Bukhroh & بكرة & $\begin{array}{l}\text { Dalam makna leksikal dan } \\
\text { bahasa fushah, kata yang } \\
\text { mempunyai arti Besok } \\
\text { adalah غدا bukan bukrah. } \\
\text { Kata بكرة merupakan bahasa } \\
\text { kolokial yang hampir dipakai } \\
\text { mayoritas Negara Arab. }\end{array}$ \\
\hline 2 & Das'ah & دسعة & $\begin{array}{l}\text { Kata ini menurut makna } \\
\text { leksikal tidak ada artinya } \\
\text { tetapi hanya digunakan dalam } \\
\text { bahasa percakapan kolokial } \\
\text { masyarakat Klego yang } \\
\text { mempunyai makna ganteng/ } \\
\text { cantik. }\end{array}$ \\
\hline 3 & Ya hanuh & يا هنوه & $\begin{array}{lrr}\text { Kata ini tidak ada } & \text { makna } \\
\text { leksikalnya } & \text { sama } & \text { sekali } \\
\text { tetapi mempunyai } & \text { makna } \\
\text { "sombong" } & \text { berdasarkan } \\
\text { konvensi } & \text { bahasa } & \text { pada } \\
\text { masyarakat } & \text { Klego } & - \\
\text { Pekalongan. } & & \\
\end{array}$ \\
\hline 4 & Bansyuf & بانشوف & $\begin{array}{l}\text { Kata ini tidak mempunyai } \\
\text { makna leksikal dalam } \\
\text { bahasa arab fushah tetapi } \\
\text { dalam bahasa arab kolokial } \\
\text { mempunyai makna "mau } \\
\text { Melihat". Huruf ب pada } \\
\text { mempunyai arti akan/mau. }\end{array}$ \\
\hline
\end{tabular}




\begin{tabular}{|c|c|c|c|}
\hline 5 & Mera 'bal & مرحبل & $\begin{array}{l}\text { Kata ini asalnya adalah حربا } \\
\text { dalam bahasa arab kolokial } \\
\text { mempunyai arti rusak/kurang } \\
\text { ajar. Ada perubahan fonetik } \\
\text { pada pengucapan masyarakat } \\
\text { Klego sehingga diucapkan } \\
\text { menjadi murahbal yang } \\
\text { mempunyai arti «nyebelin». }\end{array}$ \\
\hline 6 & Shaftah & صفطة & $\begin{array}{l}\text { Kata ini tidak mempunyai } \\
\text { makna leksikal artinya tidak } \\
\text { ada maknanya dalam kamus } \\
\text { bahasa arab manapun, kecuali } \\
\text { hanya merupakan bentuk } \\
\text { konvensi bahasa kolokial } \\
\text { masyarakat Klego yang } \\
\text { mempunyai arti bercanda. }\end{array}$ \\
\hline
\end{tabular}

\section{Implikasi konvensi bahasa terhadap harmonisasi sosial pada masyarakat Klego Pekalongan.}

Adaptasi linguistik yang terjadi pada masyarakat Klego Pekalongan memberikan satu gambaran tentang kecenderungan adanya pembentukan tatanan kehidupan masyarakat yang harmonis. Adaptasi tersebut dapat dilihat dari penutur Jawa (orang Jawa) dengan penutur Arab (etnis Arab keturunan) ketika saling berkomunikasi. Kedua penutur tersebut saling bergantian mengucapkan dua bahasa penutur yang bersangkutan.

Kalau dilihat lebih dalam bahwa adaptasi linguistik antara masyarakat Jawa dan Arab tidak hanya dalam hal leksikon tetapi juga dalam penyesuaian fonetik (bunyi), hal ini untuk memudahkan penutur bahasa yang lain untuk mengucapakan bunyi yang sama. Demikian juga penyesuaian linguistik juga dilakukan dalam tatanan gramatikal.

\section{a. Komunikasi dengan Leksikon konvensional}

Secara leksikal, pembentukan kata-kata konvensional sudah lama dilakukan oleh kedua penutur masyarakat Klego Pekalongan. Kata-kata konvensi ini sudah merupakan bahasa keseharian 
(koloqial) dan menjadi alat komunikasi antara masyarakat etnis Arab dan etnis Jawa. Dan yang lebih menarik, dalam proses komunikasi seringkali terjadi adanya pergantian kata dalam dua bahasa yang berbeda secara bergantian. Misalnya seorang etnis Jawa bertanya sama Etnis Arab dengan menggunakan kata Arab, kemudian si etnis Arab menjawabnya dengan bahasa Jawa, begitu juga sebaliknya. Dan kata-kata Arab yang digunakan si etnis Jawa tersebut adalah kata-kata Arab konvensional, dalam arti kata-kata Arab yang sudah disepakati bersama dalam komunitas Masyarakat Klego Pekalongan secara keseluruhan. Seperti contoh; Orang Arab: pak endi/ pak opo? (mau kemana/ mau apa?), maka si orang Jawa akan menjawab: regud si' (tidur dulu), syerob si' (minum dulu), gahwe si (ngopi dulu), dan lain sebagainya. Begitu juga sebaliknya jika orang Jawa bertanya pada orang Arab; ila feen?, si orang Arab akan menjawab; pak mangan (mau makan), pak turu (mau tidur), pak ngombe (mau minum), dan lain sebagainya.

Adanya saling adaptasi kebahasaan serta komunikasi dengan kata-kata konvensional yang terjadi pada masyarakat Klego Pekalongan dapat menumbuhkan keakraban dalam dalam berkomunikasi sosial.

\section{b. Adaptasi dalam wujud serapan bunyi}

Dalam tataran bunyi, apakah sebuah kebetulan atau tidak sistem fonetik kata-kata Arab konvensional cenderung dirubah serta dimiripkan dengan sistem bunyi yang ada dalam bahasa Indonesia atau jawa. Sehingga dengan adanya adaptasi bunyi dalam katakata Arab konvensional dapat memudahkan orang jawa dalam mengucapkan kata-kata tersebut. Sehingga dalam komunikasi hampir tidak ditemukan kesenjangan fasih tidaknya dalam pengucapan bunyi kata. Sebagai contoh kata 'Ajuz berubah menjadi kata Azus. Dalam kata ini terjadi perubahan atau adaptasi ponetik huruf ( $\varepsilon$ menjadi bunyi huruf ( 1 ). Begitu juga bunyi huruf $(j)$ berubah menjadi bunyi (w). Orang Jawa cenderung lebih mudah membunyikan huruf alif dan sin daripada membunyikan huruf 'ain dan zay. Sehingga ketika seorang Jawa mengucapkan kata Ajus, tekanan bunyi hampir sama ketika kata itu diucapkan oleh orang Arab. Contoh lain adalah Ta'ab menjadi ta'ap, qahwah menjadi gahwe, roja'a menjadi Reja, dan lain 
Kontribusi Konvensi Bahasa Arab - Jawa Terhadap Harmonisasi Sosial

sebagainya. Penyesuaian bunyi seperti di atas dapat memudahkan komunikasi antara kedua penutur Jawa dan Arab dalam masyarakat Klego Pekalongan.

\section{c. Adaptasi dalam wujud campur kode}

Harmonisasi sosial terbentuk semakin baik ketika adaptasi linguistik dalam komunikasi kedua penutur dilakukan dengan bentuk campur kode. Adaptasi linguistik yang berwujud campur kode antara penutur Jawa dan Arab dilakukan satu arah. Adaptasi linguistik dalam campur kode ini dimaksudkan sebagai bentuk campuran antara unsur bahasa jawa dengan bahasa Arab. Dalam hal ini pada tuturan bahasa Struktur bahasa Arab terdapat unsur-unsur bahasa Jawa, begitu juga sebaliknya. Berangkat dari batasan ini, maka adaptasi linguistik yang berupa campur kode akan teramati pada struktur kalimat yang digunakan.

Data yang diperoleh, hampir pada semua tuturan yang berupa kalimat ditemukan unsur-unsur bahasa Arab yang tersisip didalamnya bahasa Jawa, demikan juga sebaliknya. Adapun beberapa contoh tentang struktur kalimat yang berupa campur kode dapat dilihat pada struktur-struktur kalimat yang sudah dijelaskan di atas.

\section{Bentuk-bentuk relasi sosial Etnis Arab dan Jawa masyarakat Klego Pekalongan}

Persesuaian linguistik diantara etnis Arab dan etnis Jawa pada masyarakat Klego Pekalongan, sedikit besarnya mempengaruhi pada tatanan kehidupan sosial pada masyarakat tersebut. Ada beberapa implikasi sosial yeng terjadi pada kedua etnis dan penutur tersebut, yaitu;

a. Kedua etnis cenderung ingin saling mempalajari bahasa aslinya masing-masing.

b. Komunikasi sosial semakin akrab dan hangat

c. Kehidupan sosial semakin harmonis

d. Terbukanya sistem perjodohan antara dua etnis yang bersangkutan

e. Semakin banyaknya pernikahan antara etnis Arab dengan Jawa, juga sebaliknya 
Muhandis Azzuhri

\section{Simpulan}

Sejarah masyarakat komunitas Arab Klego Pekalongan tidak lepas dari sejarah kedatangan komunitas Arab ke Indonesia yang mayoritas berasal dari daerah Hadramaut -Yaman. Mereka terdiri dari dua golongan, yaitu golongan Sayyid/Alawi/Habib (Mengaku sebagai keturunan Ali bin Abi Thalib melalui jalur Husein Abi Thalib), ciri-cirinya adalah dari penamaannya mereka yaitu Al-Attas, Al-Habsyi, Idrus dan lain sebagainya dan golongan Qabili yang bukan keturunan dari Ali bin Abi Thalib, ciri mereka adalah bisa dilihat dari namanya seperti Basyir, Baswedan, Al-Katiri dan lain sebagainya.

Proses komunikasi seringkali terjadi adanya pergantian kata dalam dua bahasa yang berbeda secara bergantian. Dari beberapa konvensi bahasa yang terdapat dalam masyarakat Klego Pekalongan ternyata mempengaruhi terhadap tatanan sosialnya. Fakta bahwa di masyarakat Klego yang heterogen terjadi keharmonisan sosial yang terjalin cukup lama dan belum ada fakta yang menunjukan adanya problem, konflik horizontal, khususnya antara komunitas Arab sebagai pendatang dan komunitas Jawa sebagai pribumi. Mereka hidup rukun dan sangat harmonis, bahkan sudah terjalin ikatan pernikahan antara komunitas Jawa dan Arab, walaupun masih ditemukan secara mayoritas bahwa pihak laki-laki dari keturunan Arab dan pihak perempuan dari Jawa. 
Kontribusi Konvensi Bahasa Arab - Jawa Terhadap Harmonisasi Sosial

\section{DAFTAR PUSTAKA}

Appel, Rene, Gerad Huber, dan Guus Maijer. 1976. Sosiolinguistiek. Utrecht - Antwerpen: Het Spectrum.

Fathurrokhman. 2009. "Kode Komunikatif dalam Interaksi Sosial Masyarakat Diglosik di Pedesaan: Kajian Sosiolinguistik di Banyumas" Semarang: Fakultas Bahasa dan Seni Universitas Negeri Semarang.

Hymes, Dell. 1973. Foundations in Sosiolinguistics: An Ethnographic Approach. Phidelphia: University of Pensylvania Press.

Mahsun, 2002. Bahasa dan Relasi Sosial: Telaah Kesepadanan Adaptasi Linguistik dengan Adaptasi Sosial. Yogyakarta: Gama Media.

Sudaryanto. 1988. Metode Linguistik: Bagian Kedua Metode dan Aneka Teknik Pengumpulan Data. Yogyakarta: Gadjah Mada University Press.

1988. Metode Linguistik: Bagian Pertama ke Arah

Memahami Metode Linguistik. Yogyakarta: Gadjah Mada University Press.

Sumarsono. 2008. Sosiolinguistik. Yogyakarta: Pustaka Pelajar

Umar, Azhar dan Delvi Napitupulu. 1994. Sosiolinguistik dan Psikolinguistik: Suatu Pengantar, Medan: Pustaka Widyasarana. 
halaman ini bukan sengaja dikosongkan 